\title{
Intermediation and Economic Integration
}

\section{Citation}

Antrás, Pol, and Arnaud Costinot. 2010. Intermediation and economic integration. American Economic Review 100(2): 424-28.

\section{Published Version}

doi:10.1257/aer.100.2.424

\section{Permanent link}

http://nrs.harvard.edu/urn-3:HUL.InstRepos:4784026

\section{Terms of Use}

This article was downloaded from Harvard University's DASH repository, and is made available under the terms and conditions applicable to Open Access Policy Articles, as set forth at http:// nrs.harvard.edu/urn-3:HUL.InstRepos:dash.current.terms-of-use\#OAP

\section{Share Your Story}

The Harvard community has made this article openly available.

Please share how this access benefits you. Submit a story.

Accessibility 


\title{
INTERMEDIATION AND ECONOMIC INTEGRATION*
}

\author{
Pol Antràs \\ Harvard University and NBER \\ Arnaud Costinot \\ MIT and NBER
}

February 5, 2010

\begin{abstract}
The theory of international trade has paid scant attention to market institutions. Neither neoclassical theory nor new trade models typically specify the process by which supply and demand meet. Yet in the real world, intermediaries play a central role in materializing the gains from exchange outlined by standard trade theories. In Antràs and Costinot (2010), we have developed a stylized but explicit model of intermediation in trade. In this short paper, we present a variant of this model that illustrates the potential role of intermediaries in facilitating the realization of the gains from trade.
\end{abstract}

*Antràs: Harvard University, Cambridge, MA, pantras@fas.harvard.edu. Costinot: MIT, Cambridge, MA, costinot@mit.edu. We thank Jon Eaton, Emmanuel Farhi, Gita Gopinath, and Steve Redding for comments. This paper has been prepared for the 2010 American Economic Review Papers and Proceedings. 


\section{Introduction}

The theory of international trade has paid scant attention to market institutions. Neither neoclassical theory nor new trade models typically specify the process by which supply and demand meet. Yet in the real world, intermediaries play a central role in materializing the gains from exchange outlined by standard trade theories; see e.g. Robert C. Feenstra and Gordon H. Hanson (2004) as well as the other papers included in this session for recent evidence.

In Pol Antràs and Arnaud Costinot (2010), AC hereafter, we have developed a stylized but explicit model of intermediation in trade. In this paper, we present a variant of $\mathbf{A C}$ that illustrates the potential role of intermediaries in facilitating the realization of the gains from trade. We consider a Ricardian model with two goods and two countries. Our only point of departure from this standard model is to assume that producers do not have a direct access to centralized (Walrasian) markets. Instead, producers must be matched with a trader in order to have access to these markets. Upon matching, producers and traders bargain bilaterally.

Using this simple model, we contrast the implications of changes in the integration of Walrasian markets, which we refer to as $\mathrm{W}$-integration, with the implications of changes in the access to these markets, which we refer to M-integration. The former type of integration aims to shed light on the consequences of convergence in goods prices across countries in the presence of intermediaries, while the latter seeks to capture the consequences of the entry of foreign intermediaries in local markets, whether such intermediaries are trading companies, banks, or multinational companies in practice.

We find that $\mathrm{W}$-integration produces effects similar to those in the standard model, and in particular, makes all agents in the world (weakly) better off, despite the fact that our model features two distinct types of agents. By contrast, we show that M-integration has opposite effects on the steady-state welfare of farmers and traders and may lead to aggregate losses from trade. Although M-integration resembles a form of factor migration in neoclassical trade models, the potentially perverse welfare effects of this type of integration stem from a new and distinct channel, which does not require any worsening of a country's terms of trade. To us, these admittedly stylized results point towards the importance of explicitly modelling market institutions in an international context.

The rest of the paper is organized as follows. Section I describes the basic environment. Section II characterizes the steady state equilibrium under autarky. Section III analyses the consequences of W- and M-integration. Section IV concludes by briefly describing how our analytical results may help shed light on the consequences of agricultural trade reforms in Africa.

\section{The Basic Environment}

Preferences. Consider an island inhabited by a continuum of infinitely lived agents with mass $N$ that consume two goods, coffee $(C)$ and sugar $(S)$. Agents aim to maximize the expected value of 
their lifetime utility

$$
V=E\left[\int_{0}^{+\infty} e^{-r t} v(C(t), S(t)) d t\right]
$$

where $v$ is increasing, concave, homogeneous of degree one and satisfies standard Inada conditions. Under these assumptions, both goods are essential in consumption: $v(0, S)=v(C, 0)=0$ for all $C$ and $S$.

Endowments and Technology. There are two types of agents, farmers $(F)$ and traders $(T)$. We denote by $N_{F}$ and $N_{T}$ the measures of farmers and traders on the island. Farmers are endowed with a plot of land that allows them to grow an amount $1 / a_{C}$ of coffee or an amount $1 / a_{S}$ of sugar per unit of time. Goods are not storable and a farmer is unable to grow both goods at the same date $t$. We denote by $\gamma \in[0,1]$ the endogenously determined share of farmers growing coffee at a given date. In order to be able to sell part of their output and consume both goods, a farmer needs to find a trader, and doing so may take time due to search frictions. Traders are not endowed with land but have the expertise necessary to access centralized (Walrasian) markets in which coffee and sugar are exchanged under competitive conditions. We denote by $p \equiv p_{C} / p_{S}$ the relative price of coffee in that market.

Matching. Farmers and traders can be in one of two states, matched $(M)$ or unmatched $(U)$. We denote by $u_{F}$ and $u_{T}$ the mass of unmatched farmers and traders at any point in time. Unmatched farmers and traders come together randomly. The number of matches per unit of time is given by a matching function, $m\left(u_{F}, u_{T}\right)$, which is increasing, concave, homogeneous of degree one and satisfies standard Inada conditions. The associated rate at which unmatched farmers meet unmatched traders is equal to $\mu_{F}(\theta) \equiv m(1, \theta)$, with $\theta \equiv u_{T} / u_{F}$. The rate at which unmatched traders meet unmatched farmers is in turn given by $\mu_{T}(\theta) \equiv m(1 / \theta, 1)=\mu_{F}(\theta) / \theta$. We refer to $\theta$ as the level of 'intermediation' on the island. We also assume that existing matches are destroyed at an exogenous Poisson rate $\lambda>0$.

Bargaining. When a farmer and a trader form a match, they negotiate the (relative) price at which the trader will purchase the output in the hands of the farmer. This 'farm-gate' price will naturally differ from the competitive one $(p)$ and will reflect the (primitive) bargaining power of agents as well as their outside options. We model these negotiations by means of the generalized Nash bargaining solution, and assume that traders capture a fraction $\beta$ of the ex-post gains from trade. Because both parties have symmetric information, bargaining will be (bilaterally) efficient. Let $V_{F_{i}}^{M}$ denote the value function of a farmer matched with a trader and producing good $i=C, S$; and let $V_{F}^{U}$ denote the value function of an unmatched farmer. Similarly, let $V_{T_{i}}^{M}$ denote the value function of a trader matched with a farmer carrying good $i$; and $V_{T}^{U}$ denote the value function of an unmatched trader. Formally, the Nash bargaining consumption levels of a farmer-trader match with good $i,\left(C_{F_{i}}, S_{F_{i}}, C_{T_{i}}, S_{T_{i}}\right)$, solve

$$
\max _{C_{F_{i}}, S_{F_{i}}, C_{T_{i}}, S_{T_{i}}}\left(V_{T_{i}}^{M}-V_{T}^{U}\right)^{\beta}\left(V_{F_{i}}^{M}-V_{F}^{U}\right)^{1-\beta}
$$


subject to $p C_{F_{i}}+S_{F_{i}}+p C_{T_{i}}+S_{T_{i}} \leq\left(p / a_{C}\right) \cdot \mathcal{I}_{C}+\left(1 / a_{S}\right)\left(1-\mathcal{I}_{C}\right)$, where $\mathcal{I}_{C}=1$ if the farmer carries coffee and $\mathcal{I}_{C}=0$, otherwise. The negotiated bilateral relative price can easily be retrieved from these consumption levels.

Timing of Events. Each date $t$ is divided into two periods. In the first period, farmers decide which goods to produce and matched farmers and traders bargain over the exchange of goods. In the second period, matched traders carry out transactions in Walrasian markets, consumption takes place, new matches are formed among unmatched agents, and a fraction of existing matches is dissolved exogenously.

\section{$3 \quad$ Steady State Equilibrium}

We define a steady state equilibrium as: $(i)$ a relative price, $p ;(i i)$ a share of coffee farmers, $\gamma ;($ iii $)$ a vector of consumption levels, $\left(C_{F_{i}}, S_{F_{i}}, C_{T_{i}}, S_{T_{i}}\right)$ for $i=C, S$; and (iv) an intermediation level, $\theta$, such that: $(i)$ Walrasian markets clear; (ii) consumption levels are determined by Nash bargaining; and (iii) the number of matches created is equal to the number of matches destroyed.

It is straightforward to see that under autarky we must have $V_{F_{C}}^{M}=V_{F_{S}}^{M} \equiv V_{F}^{M}$ and $V_{T_{C}}^{M}=$ $V_{T_{S}}^{M} \equiv V_{T}^{M}$ if both goods are to be produced in equilibrium. This in turn can be shown to imply that $\left(C_{F_{C}}, S_{F_{C}}\right)=\left(C_{F_{S}}, S_{F_{S}}\right) \equiv\left(C_{F}, S_{F}\right)$ and $\left(C_{T_{C}}, S_{T_{C}}\right)=\left(C_{T_{S}}, S_{T_{S}}\right) \equiv\left(C_{T}, S_{T}\right)$, so we can write the Bellman equations characterizing the expected lifetime utilities of agents as follows:

$$
\begin{aligned}
r V_{F}^{U} & =\mu_{F}(\theta)\left(V_{F}^{M}-V_{F}^{U}\right), \\
r V_{F}^{M} & =v\left(C_{F}, S_{F}\right)+\lambda\left(V_{F}^{U}-V_{F}^{M}\right), \\
r V_{T}^{U} & =\mu_{T}(\theta)\left(V_{T}^{M}-V_{T}^{U}\right), \\
r V_{T}^{M} & =v\left(C_{T}, S_{T}\right)+\lambda\left(V_{T}^{U}-V_{T}^{M}\right) .
\end{aligned}
$$

Unmatched farmers get zero instantaneous utility and become matched at rate $\mu_{F}(\theta)$, while matched farmers get a flow utility of $v\left(C_{F}, S_{F}\right)$ and become unmatched at rate $\lambda$. Similarly, unmatched traders receive zero utility and get matched at rate $\mu_{T}(\theta)$, while matched traders get utility $v\left(C_{T}, S_{T}\right)$ and become unmatched at rate $\lambda$.

We can now describe how the process of intermediation and Nash bargaining between farmers and traders affects the division of surplus and the implied terms of exchange of goods $C$ and $S$. Nash bargaining imposes the following condition

$$
V_{T}^{M}-V_{T}^{U}=\beta\left(V_{T}^{M}+V_{F}^{M}-V_{F}^{U}-V_{T}^{U}\right),
$$

as well as

$$
\frac{v_{C}\left(C_{F}, S_{F}\right)}{v_{S}\left(C_{F}, S_{F}\right)}=\frac{v_{C}\left(C_{T}, S_{T}\right)}{v_{S}\left(C_{T}, S_{T}\right)}=p
$$

and

$$
p C_{F}+S_{F}+p C_{T}+S_{T}=p / a_{C}=1 / a_{S} .
$$


Equation (5) states that traders get a share $\beta$ of the surplus of any match, while equations (6) and (7) reflect the fact that Nash bargaining outcomes are Pareto efficient, in the sense that the agents' marginal rates of substitution are equated, and the budget constraint is satisfied with equality. Equation (7) implies that the only relative price of coffee consistent with equilibrium is

$$
p=a_{C} / a_{S}
$$

It is identical to the relative price that would apply in a frictionless Ricardian model in which farmers had direct access to Walrasian markets. Imposing goods-market clearing, it can also be verified that the share of coffee farmers $\gamma$ and the joint consumption of coffee, $\bar{C} \equiv C_{F}+C_{T}$, and sugar, $\bar{S} \equiv S_{F}+S_{T}$, of a matched pair are identical to those obtained by a representative consumer in a Ricardian model.

Denote by $\alpha \in(0,1)$ the share of joint consumption that is captured by the trader, with the remaining share $1-\alpha$ accruing to the farmer. Equation (6) ensures that this share is common for both goods. Naturally, a higher $\alpha$ is associated with a distribution of surplus that is more favorable to the trader. Manipulation of equations (1)-(5) implies that in the autarky equilibrium, the share $\alpha$ is given by

$$
\alpha=\beta \frac{r+\lambda+\mu_{T}(\theta)}{r+\lambda+(1-\beta) \mu_{F}(\theta)+\beta \mu_{T}(\theta)} .
$$

Equation (8) illustrates that the share $\alpha$ of goods captured by the trader is increasing in the primitive bargaining power of traders and decreasing in the ratio $\theta$ of unmatched traders to unmatched farmers. Intuitively, a higher value of $\theta$ enhances the payoff of farmers in case of a negotiation failure, as it reduces the expected time they will have to wait for a new trading opportunity. The value of $\alpha$ can be interpreted as the traders' 'margins' since $\alpha$ can be shown to equal the (percentage) difference between the relative price in the Walrasian markets and the relative price at which farmers sell their goods to traders.

Finally, the equality between the number of matches created and destroyed imposes $\dot{u}_{F}=$ $\dot{u}_{T}=0$, from which we obtain the equilibrium level of intermediation $\theta$ as a function of matching parameters and the ratio $N_{T} / N_{F}$ :

$$
\frac{\lambda \theta+\mu_{F}(\theta)}{\lambda+\mu_{F}(\theta)}=\frac{N_{T}}{N_{F}}
$$

Because the left-hand side of (9) is increasing in $\theta$, and it has a range equal to $(0,+\infty)$, we can conclude that there exists a unique steady-state equilibrium level of $\theta$. Furthermore, the equilibrium value of $\theta$ is increasing in the ratio of traders to farmers on the island. In light of equation (8), this in turn implies that traders' margins tend to be lower in islands where traders are relatively more abundant. 


\section{Economic Integration}

We now turn to a world economy comprising two islands, North and South, of the type described above. The islands only differ in terms of their ratios of traders to farmers and their production technologies. We denote Southern variables with asterisks. In order to avoid a taxonomic exercise, we restrict ourselves to the case in which traders are abundant in the North and this country has comparative advantage in the production of sugar. This amounts to assuming $(i) N_{T} / N_{F}>N_{T}^{*} / N_{F}^{*}$; and $(i i) a_{C} / a_{S}>a_{C}^{*} / a_{S}^{*}$.

Within our simple model, the two islands can become economically integrated in two distinct manners. A first possibility is that the centralized markets where traders exchange goods become global rather than local, while maintaining the assumption that farmers can only trade with local traders. We refer to this type of integration - the integration of two initially isolated Walrasian markets - as $W$-integration. A second possibility is to model economic integration as the internationalization of trading opportunities, in the sense that traders worldwide are allowed to intermediate trade in either of the two islands. We refer to this type of integration - the integration of two initially isolated matching markets - as M-integration.

\subsection{W-Integration}

Our model comprises two blocks: (i) Walrasian markets; and (ii) bilateral exchanges governed by bargaining and matching. We next study how these two blocks are affected by W-integration.

In the absence of trade costs, $\mathrm{W}$-integration will necessarily equate the relative price at which traders worldwide can exchange goods in both markets. As in the standard Ricardian model, there will be three types of equilibria depending on whether or not one of the two countries remains diversified in production. If North remains diversified, then $p^{W}=a_{C} / a_{S}$, and the joint income of a matched farmer-trader pair in the South is strictly higher if the farmer grows coffee. As a result, all Southern farmers will immediately specialize in coffee production. Conversely, if farmers in the South remain diversified, then $p^{W}=a_{C}^{*} / a_{S}^{*}$ and Northern farmers fully specialize in producing sugar. The third type of equilibrium is one in which both North and South fully specialize in their comparative advantage good and $a_{C}^{*} / a_{S}^{*}<p^{W}<a_{C} / a_{S}$. It is straightforward to show that the joint instantaneous utility levels achieved by Southern and Northern matched farmer-trader pairs (i.e., $v\left(\bar{C}^{* W}, \bar{S}^{* W}\right)$ and $v\left(\bar{C}^{W}, \bar{S}^{W}\right)$, respectively) are (weakly) increased by W-integration, with the increase being strict for pairs located in a country that fully specializes.

How does W-integration affect the terms of bilateral exchanges? Since traders can only match with farmers from their own island, the steady-state ratio of unmatched farmers to traders on both islands remains unaffected by $\mathrm{W}$-integration and continues to be given by equation (9). Furthermore, because traders' margins in equation (8) are independent of the instantaneous joint utility levels, it must be the case that traders' margins are also unaffected by W-integration. In other words, the income of farmers either remains unaffected or grows proportionally with the improvement in the terms of trade brought about by W-integration. Despite the endogeneity of traders' 
margins, W-integration has no distributional effects.

Given these results, inspection of the value functions in (1)-(4) implies that

Proposition 1 W-integration: ( $i)$ has no effect on traders' margins; (ii) and makes all agents in the world (weakly) better off.

Since W-integration is similar to the type of economic integration considered in standard trade models, it should not be too surprising that it delivers similar effects. In AC, we have shown however that allowing for the endogenous entry of traders modifies the previous conclusions in two important ways. First, the increase in joint utility levels caused by $\mathrm{W}$-integration induces the entry of new traders and necessarily raises the equilibrium level of intermediation $(\theta)$ in islands that fully specialize. Second, this endogenous change in the level of intermediation necessarily reduces traders' margins and magnifies the gains from trade predicted by standard models.

\subsection{M-Integration}

We now turn to a situation in which traders are allowed to search for farmers in both islands (though they can only search in one of these two islands at any point in time). We refer to this process as the integration of matching markets, or simply M-integration. We will show below that the welfare implications of this type of integration are much more nuanced. As in section III.4.1, we assume that the two islands are initially under autarky when M-integration takes place.

In the absence of global Walrasian markets, it is immediate that M-integration will have no effect on the relative prices $p$ and $p^{*}$ at which coffee and sugar are traded in the two local markets. Nevertheless, under M-integration, traders might now have an incentive to start searching for

trading opportunities on another island. To study this decision formally, let us compute the autarkic steady-state lifetime utilities of unmatched traders located in the North and the South (matched traders will never switch islands if search frictions are large enough, which we implicitly assume). From equations (3), (4), and (8), we have that

$$
\begin{aligned}
r V_{T}^{U} & =\frac{\beta \mu_{T}(\theta) v(\bar{C}, \bar{S})}{r+\lambda+(1-\beta) \mu_{F}(\theta)+\beta \mu_{T}(\theta)}, \\
r V_{T^{*}}^{U} & =\frac{\beta \mu_{T}\left(\theta^{*}\right) v\left(\bar{C}^{*}, \bar{S}^{*}\right)}{r+\lambda+(1-\beta) \mu_{F}\left(\theta^{*}\right)+\beta \mu_{T}\left(\theta^{*}\right)},
\end{aligned}
$$

where $\theta$ and $\theta^{*}$ are implicitly defined by equation (9). There are two reasons why these lifetime utilities might be different. First, production technologies are different in the two countries and, other things equal, traders want to intermediate exchanges in economies where farmers are more productive. Second, the autarkic ratio of traders to farmers also differs across islands and, other things equal, traders prefer to locate in islands where this ratio is low because margins in those islands are higher and the expected frequency with which they conduct trades is also higher.

Given that the North is abundant in traders under autarky, $\theta>\theta^{*}$, if production technologies are sufficiently similar across countries, M-integration will necessarily be associated with a movement 
of traders from North to South, which will increase $\theta^{*}$ in the South and will reduce it in the North (though these values will not be equalized as long as $v(\bar{C}, \bar{S}) \neq v\left(\bar{C}^{*}, \bar{S}^{*}\right)$ ). By contrast, if farmers in the South are sufficiently inefficient $\left(a_{C}^{*}\right.$ or $a_{S}^{*}$ are sufficiently high), Northern traders will not want to operate in the South and the ratio of unmatched traders to farmers on the two islands will diverge as a result of M-integration.

What are the welfare effects of M-integration in each island? Straightforward manipulation of the value functions implies that

Proposition 2 M-integration: (i) has opposite effects on the steady-state welfare of farmers and traders; (ii) may lead to aggregate losses from trade in one island if the primitive bargaining power of the set of agents made worse off is sufficiently high.

Result $(i)$ states that M-integration necessarily generates distributional conflict between farmers and traders. If M-integration increases the ratio of traders to farmers on an island, then native matched and unmatched traders from that island will be worse off, while matched and unmatched farmers on that island will be made better off. Intuitively, the entry of traders simultaneously reduces traders' margins and increases (decreases) the rate at which traders (farmers) find matches. This effect is similar to that generated by factor migration in a standard two-factor model. Result (ii), however, is novel in that M-integration may well reduce aggregate welfare in one of the two islands. Which island (if any) loses depends on the value of the bargaining weight $\beta$, the extent of technology differences across islands and differences in the ratio of native traders and farmers across islands.

In order to better understand this result, consider the following extreme example. Suppose that the primitive bargaining of traders is extremely large $(\beta \rightarrow 1)$, the two countries share the same production technologies $\left(v(\bar{C}, \bar{S})=v\left(\bar{C}^{*}, \bar{S}^{*}\right)\right)$, and $N_{T} / N_{F}>N_{T}^{*} / N_{F}^{*}$. Then, traders will move from North to South, which will make Southern farmers better off and Southern native traders worse off. Nevertheless, by letting $\beta \rightarrow 1$, the gain obtained by farmers becomes arbitrarily close to 0 , while the loss of rents by Southern traders remains positive. Interestingly, the possibility of aggregate losses under M-integration extends to environments where traders do not earn any rents. In AC, we allow for the endogenous entry of traders (as well as transitional dynamics), yet aggregate losses remain possible whenever the (primitive) bargaining power of traders differ in the two islands. The key behind the inefficiency in this alternative environment is the trading externality underlying the search friction (see AC for details).

\section{Discussion}

The previous model is admittedly stylized. It does not aspire to capture the precise workings of any particular market. The search frictions in our model rather aim to reflect, in a somewhat reducedform way, the set of frictions that inhibit the ability of producers to single-handedly place their goods in world markets, regardless of whether these frictions actually derive from time-consuming 
search, or rather from incomplete information about quality and prices, or working-capital needs. We believe, however, that this framework may be particularly well-suited for analyzing the role of itinerant traders in certain agricultural markets in Africa (see e.g. Marcel Fafchamps and Ruth V. Hill, 2005).

Our simple model illustrates that the consequences of economic integration in the presence of intermediation may be very different from those predicted by standard models. It provides a useful lens through which to interpret the disappointing effects of recent episodes of trade liberalization in Africa. For example, Margaret McMillan, Dani Rodrik and Karen H. Welch (2003) study the case of the cashew sector in Mozambique, in which the removal of restrictions on exports of raw cashews generated only small increases in farm-gate prices, while substantially diminishing the aggregate income of Mozambiquean agents trading and processing cashews, and benefitting Indian importers of raw cashews. In our view, the analysis of market institutions in international trade is a

promising avenue of future research and can greatly enhance our understanding of the consequences of globalization in developing economies.

\section{REFERENCES}

Antràs, Pol, and Arnaud Costinot. 2010. "Intermediated Trade," mimeo Harvard University.

Fafchamps, Marcel and Ruth V. Hill. 2005. "Selling at the Farm-Gate or Travelling to Market," American Journal of Agricultural Economics, 87(3), pp. 717-34.

Feenstra, Robert C. and Gordon H. Hanson. 2004. "Intermediaries in Entrepôt Trade: Hong Kong Re-Exports of Chinese Goods," Journal of Economics and Management Strategy, 13:1, pp. 3-35.

McMillan, Margaret, Dani Rodrik and Karen H. Welch. 2003. "When Economic Reform Goes Wrong: Cashews in Mozambique," Brookings Trade Forum, pp. 97-165. 